\title{
Bromocriptine in Parkinsonism: long-term treatment, dose response, and comparison with levodopa
}

\author{
J. D. PARKES, A. G. DEBONO, AND C. D. MARSDEN \\ From The University Department of Neurology, King's College Hospital, and \\ Institute of Psychiatry, London
}

SYNOPSIS Thirty-seven patients with Parkinsonism were treated with bromocriptine 2.5-300 mg daily. Bromocriptine, alone or combined with levodopa, caused a $20-30 \%$ reduction in disability scores in 11 patients treated for one year. Tolerance did not develop during this period. Bromocriptine treatment was not of value in six patients who had previously not responded or who had lost their response to levodopa. However, in four of five patients with response swings on levodopa due to rapid changes in plasma dopa levels, the addition of bromocriptine caused a more stable response. Dose response curves to bromocriptine $12.5,25,50$, and $100 \mathrm{mg}$ and to levodopa 250, 500, 1000, and $2000 \mathrm{mg}$ were studied in seven patients. Levodopa $2 \mathrm{~g}$ had a greater therapeutic effect and caused a greater rise in plasma growth hormone concentration than bromocriptine $100 \mathrm{mg}$. Levodopa caused emesis more commonly and hallucinations less commonly than bromocriptine. Bromocriptine appears to be a less potent stimulant than dopamine, and has both pre- and post-synaptic effects. Metoclopramide $60 \mathrm{mg}$ oral was given 30 minutes before bromocriptine or levodopa to establish whether this caused dopamine-receptor blockade. Metoclopramide acted as a competitive antagonist to the antiParkinsonism and growth hormone effect of both drugs and in individual cases prevented emesis and hallucinations. The fall in blood pressure due to bromocriptine or levodopa was not antagonised by metoclopramide. Central and peripheral vascular dopamine receptors may be different in nature.

Bromocriptine, $2 \mathrm{Br}$ alpha-ergocryptine, is an ergot alkaloid with pre- and post-synaptic effects on dopamine neurone systems. It has the pharmacological property of causing dopamine receptor stimulation (Corrodi et al., 1973) and also has pre-synaptic actions which are prevented when dopamine synthesis is blocked by inhibition of the enzyme tyrosine hydroxylase (Johnson et al., 1976). In addition to these actions of bromocriptine on dopamine systems, bromocriptine affects many other different amine-neurotransmitters in the brain, causing stimulation of serotonin receptors and possibly blockade of noradrenaline receptors (Corrodi et al., 1975).

Bromocriptine suppresses lactation and causes an increase in plasma growth hormone concentration in normal subjects, although in acromegalics plasma growth hormone levels are reduced (Pozo et al., 1972; Cammani et al., 1975). These hormonal changes are

(Accepted 13 July 1976.) likely to result from the action of bromocriptine on dopamine neurones and receptors in the pituitary and hypothalamus. Because of this action on dopamine receptors, Calne et al. (1974) used bromocriptine to treat patients with Parkinson's disease and showed this drug had a definite antiParkinsonism action and similar side effects to levodopa.

We have investigated the effects of bromocriptine treatment of Parkinson's disease to see whether this has any practical advantage over levodopa. Major problems of levodopa treatment include lack of response and response swings related to rapid changes in plasma dopa levels (Marsden and Parkes, 1976), as well as dose limitation due to dyskinesias. We have used bromocriptine instead of levodopa to treat patients who have not responded to levodopa and others with severe response fluctuations related to changes in plasma dopa levels. We also report the results of a year's treatment of patients with Parkinson's disease with bromocriptine, alone or combined with levodopa. To show whether bromo- 
criptine mimics the action of dopamine, we have studied dose-response curves to bromocriptine and levodopa.

\section{METHODS}

\section{BROMOCRIPTINE DOSE-RESPONSE CURVES}

Dose-response curves to bromocriptine 12.5, 25, 50, and $100 \mathrm{mg}$ were established in seven patients with idiopathic Parkinson's disease, five male and two female, aged 53 to 72 years (mean age 59 years). The disability of five of these patients was moderate (total disability score 20-50) and of two was severe (disability score above 50). Patients were selected for bromocriptine treatment as they could tolerate high bromocriptine dosages (100-300 mg daily) with improvement in the features of Parkinsonism without severe side effects. The detailed effects of different doses of bromocriptine in six of these patients are described elsewhere (Debono et al., 1976).

\section{LEVODOPA DOSE-RESPONSE CURVES}

Dose-response curves to levodopa 250,500, 1000, and $2000 \mathrm{mg}$ were established in the above patients. The assessment of clinical response to levodopa was different from that for bromocriptine. Levodoparesponse was determined by the reduction in total disability scores and sub-scores after one to four months of treatment on each separate levodopa dosage.

\section{METOCLOPRAMIDE PRETREATMENT}

Metoclopramide pretreatment was studied in four of the above patients. Metoclopramide is an antiemetic drug commonly used to prevent levodopainduced emesis. Although metoclopramide in low or moderate doses frequently causes acute dystonic reactions, drug-induced Parkinsonism is very rare. Metoclopramide has the pharmacological property of causing dopamine receptor blockade (Peringer $e t$ al., 1976). Metoclopramide $60 \mathrm{mg}$ was given by mouth 30 min before bromocriptine or levodopa.

\section{RESPONSE ASSESSMENT}

The effects of the different doses of bromocriptine or levodopa alone, or preceded by metoclopramide, on movement, dyskinesias, blood pressure, and plasma growth hormone concentration were determined in the above patients. Akinesia, tremor, postural deformity, rigidity, and total functional disability were determined at 30 minute intervals by a single observer using a score proforma as previously described (Marsden et al., 1973). This observer did not know whether the patient had received metoclo- pramide pretreatment or not. The severity and nature of dyskinesias, whether predominantly dystonic, choreic, or both, were documented. The blood pressure, lying and standing, was measured at 30 minute intervals, and the mean arterial pressure (MAP: diastolic plus $1 / 3$ pulse pressure) was determined.

\section{GROWTH HORMONE DETERMINATION}

Venous blood was taken by indwelling forearm catheter at 30 minute intervals over a 4.5 hour period before and after bromocriptine or levodopa was given and the plasma concentration of growth hormone determined by the method of Schalch and Parker (1964).

Four patients were given four separate different dosages of bromocriptine $(12.5,25,50$, and $100 \mathrm{mg})$ on four separate occasions at one week intervals, two patients were given three dosages $(25,50$, and $100 \mathrm{mg})$ and one patient two dosages $(25$ and $100 \mathrm{mg})$. Four patients were given three separate dosages of levodopa. Metoclopramide pretreatment was given to one patient before each of four separate doses of bromocriptine and three separate doses of levodopa, to one patient before three doses of both drugs, and to two patients, before two doses of both drugs.

\section{ONE-YEAR BROMOCRIPTINE TREATMENT}

During the year 1975-76, 37 patients were treated with bromocriptine, 11 for one year, and 26 for shorter periods. Treatment was discontinued in 17 of these 26 patients because of adverse reactions or failure to show useful improvement.

Eleven patients with idiopathic Parkinson's disease, six male and five female, aged 51-72 years (mean age 62 years) were treated with bromocriptine for one year. In these 11 subjects, before bromocriptine treatment, patient disability was slight in one (total disability 20), moderate in five (score 20-50), and severe in five (score greater than 50). Two of these patients were taking levodopa 0.5 and $1.5 \mathrm{mg}$ daily respectively, five Sinemet (levodopa $250 \mathrm{mg}$ combined with 1-alpha methyl dopa hydrazine $25 \mathrm{mg}$ ) three to six tablets daily, and four were not taking levodopa. Eight patients were taking anticholinergic drugs and six amantadine.

These patients were selected for bromocriptine treatment as despite levodopa they remained significantly disabled. In patients not on levodopa there was a therapeutic response to bromocriptine without dose-limiting adverse reactions.

\section{LEVODOPA-FAILURES}

Six patients, three men and three women, aged 55-70 years (mean age 62 years), with the initial diagnosis of 
idiopathic Parkinson's disease, two who had not responded to prolonged treatment with levodopa and four who had lost initial response to levodopa after one to two years' treatment, were treated with bromocriptine. The cause of levodopa failure was not identified accurately in these patients. However, in the two subjects who did not respond the diagnosis may have been striatonigral degeneration (in which the levodopa response is very limited) rather than idiopathic Parkinson's disease since both had no tremor and were mildly demented. In the other patients levodopa absorption may have been erratic and after a standard oral load of $1.0 \mathrm{~g}$ levodopa, mean peak plasma dopa levels were low $(2.5 \pm 0.5 \mu \mathrm{mol} / \mathrm{l})$, compared with $4.6 \pm 0.5 \mu \mathrm{mol} / 1$ in 18 patients who maintained a good therapeutic response.

\section{LEVODOPA SWINGERS}

Five patients with idiopathic Parkinson's disease, four male and one female aged 56-69 years, who had developed response swings on levodopa because of fluctuations in plasma dopa levels were treated additionally with bromocriptine. In these five patients the response to levodopa during the initial one to two years of treatment had been fairly stable over a 12 hour period but subsequently marked diurnal variations occurred, periods of good response occurring at the time of high plasma dopa levels and poor response when levels were low. These patients, who were all severely disabled during 'off' periods, also had other types of response swings with freezing episodes and occasional periods of impaired mobility due to the presence of severe dyskinesias.

\section{BROMOCRIPTINE TREATMENT}

In all patients bromocriptine was started in low dosage, a single oral $2.5 \mathrm{mg}$ dose being given to establish whether this was tolerated. Dosage was increased by $2.5 \mathrm{mg}$ on alternate days and increased until a therapeutic effect occurred or side-effects limited dosage. With increasing experience of bromocriptine during the year 1975-76, it was found that high dosages were well tolerated by some subjects and in individual patients optimum dosage was established as $\mathbf{2 . 5}-\mathbf{3 0 0} \mathrm{mg}$ daily. The higher dosages were given in three or four divided doses throughout the day. Bromocriptine rarely caused nausea when given either before or after meals. In the 11 patients treated with bromocriptine for one year mean dosage at one year was $72 \mathrm{mg}$ daily; in the six levodopa failures bromocriptine dosage was $40 \mathrm{mg}$ (five patients) and $90 \mathrm{mg}$ (one patient), and in the five patients with response swings on levodopa, bromocriptine dosage was $10,60,100,150$, and $300 \mathrm{mg}$ daily respectively, given in addition to levodopa.

\section{RESULTS}

\section{BROMOCRIPTINE AND LEVODOPA DOSE-RESPONSE}

Changes in mobility, plasma growth hormone concentration, and mean arterial blood pressure in patients with Parkinson's disease after separate doses of bromocriptine and levodopa are shown in Fig. 1. Levodopa $2 \mathrm{~g}$ was a slightly more potent antiParkinsonism drug than bromocriptine $100 \mathrm{mg}$ and caused a greater elevation in plasma growth hormone concentration. Orofacial dyskinesia and choreic limb movements occurred at the time of peak therapeutic response in six of seven patients on bromocriptine and in the same patients, separately when on levodopa (Table 1). The single patient who did not develop dyskinesias on bromocriptine also did not show involuntary movements with levodopa.

Both bromocriptine $100 \mathrm{mg}$ and levodopa $2 \mathrm{~g}$ caused a fall in erect and supine blood pressure of around $20 \mathrm{mmHg}$ in most but not all patients. No patient had symptoms of postural hypotension.

The shape of the anti-Parkinsonism, growth hormone, and blood pressure dose-response curves for bromocriptine was broadly similar to those for
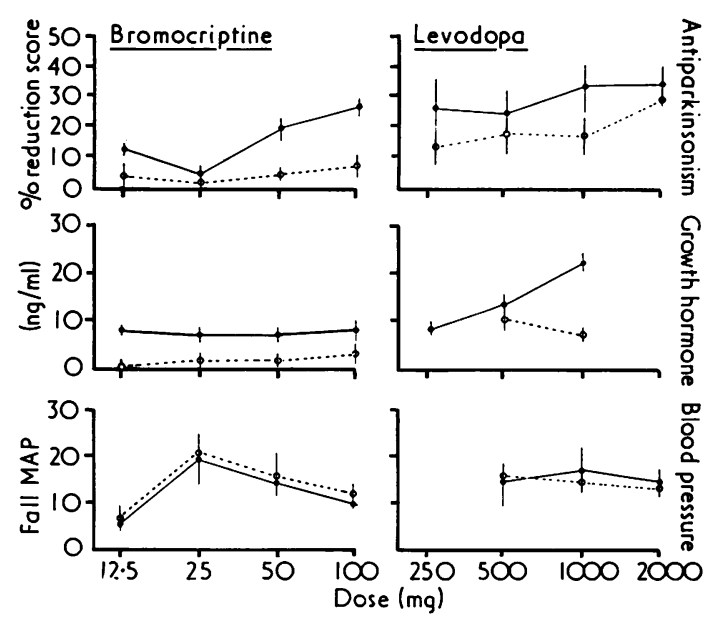

FIG. 1 Dose-response curves to bromocriptine and levodopa. Mean anti-Parkinsonism (percentage reduction in total disability score), growth hormone (peak plasma concentration, $\mathrm{ng} / \mathrm{ml}$ ), and blood pressure (fall in erect mean arterial pressure; $\mathrm{mmHg}$ ) response ( \pm ISEM) to bromocriptine, 12.5, 25, 50, and $100 \mathrm{mg}$, in seven patients with Parkinsonism. Responses in the same patients to levodopa 250,500, 1000, and $2000 \mathrm{mg}$, and the effect of metoclopramide $60 \mathrm{mg}$ pretreatment is shown. Bromocriptine or levodopa alone, . . . . . Metoclopramide pretreatment. 
TABLE 1

MEAN \% REDUCTION IN TOTAL DISABILITY SCORE, AND RISE IN PLASMA GROWTH HORMONE CONCENTRATION ( \pm 1 SEM) IN PATIENTS WITH PARKINSON'S DISEASE, GIVEN BROMOCRIPTINE AND IN FOUR OF THE SAME PATIENTS GIVEN METOCLOPRAMIDE $60 \mathrm{mg} 30$ MINUTES BEFORE BROMOCRIPTINE

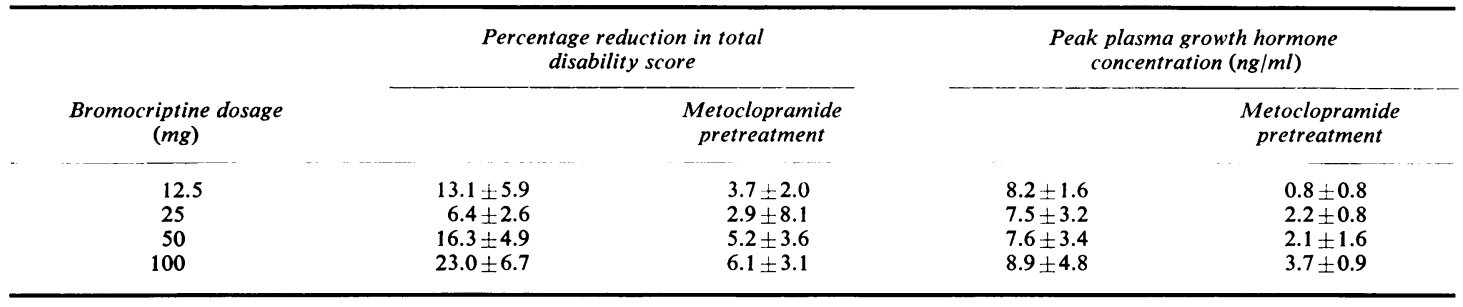

levodopa. In individual patients, high bromocriptine and levodopa dosages were usually, but not always, more effective than low dosages in all these respects. However, two patients had a lesser anti-Parkinsonism response to bromocriptine 50 and $100 \mathrm{mg}$ than to $25 \mathrm{mg}$, and the fall in erect and supine MAP was of greatest magnitude after bromocriptine $25 \mathrm{mg}$ $(19 \pm 6 \mathrm{mmHg}$ fall in erect MAP, and $20 \pm 5 \mathrm{mmHg}$ fall in supine MAP). The mean rise in peak plasma growth hormone concentration was approximately equal after all doses of bromocriptine.

Levodopa, but not bromocriptine, caused nausea, sometimes accompanied by vomiting, in three of seven subjects.

\section{RELATION BETWEEN ANTI-PARKINSONISM AND GROWTH HORMONE RESPONSE}

There was no statistically significant relationship between the clinical response to levodopa and the rise in plasma growth hormone concentration after a single dose. However, in all patients given bromocriptine, irrespective of dosage, the increase in plasma growth hormone concentration was related to the degree of clinical response as shown by the percentage reduction in total disability score over a period of four hours $(r=0.41, n=24, \mathrm{P}<0.05$, Fig. 2$)$.

\section{METOCLOPRAMIDE PRETREATMENT}

Metoclopramide in high dosage $(60 \mathrm{mg})$ was a competitive antagonist to the anti-Parkinsonism and growth hormone effects of both levodopa and bromocriptine. In addition, metoclopramide abolished nausea and emesis due to levodopa. Dyskinesias due separately to levodopa and bromocriptine were less severe after metoclopramide pretreatment, although still detectable. In contrast, metoclopramide had no effect on the bromocriptine or levodopa-induced fall in blood pressure.

Metoclopramide $60 \mathrm{mg}$ given singly to four patients with idiopathic Parkinson's disease on no treatment did not cause any change in mean total disability scores, plasma growth hormone concentration, or blood pressure.

Blood bromocriptine levels were not determined. Mean peak plasma dopa levels after levodopa 500 , 1000 , and $2000 \mathrm{mg}$ were 5.6, 7.9, and $11.1 \mu \mathrm{mol} / \mathrm{l}$ respectively. Metoclopramide pretreatment caused a slight increase in peak plasma dopa levels.

\section{ONE YEAR'S BROMOCRIPTINE TREATMENT}

Eleven patients, seven on levodopa and four not on levodopa, were treated with bromocriptine for one year. In patients not on levodopa improvement due to bromocriptine occurred within two to seven days of starting treatment. In most patients optimum bromocriptine dosage and optimum response were established within the first four to eight weeks of bromocriptine treatment, although higher dosages were used in the second six month period of trial. During the treatment year bromocriptine caused around $20 \%$ reduction in total disability and subscores both in patients on and off levodopa (Table 2). There was no failure of bromocriptine response during the year of treatment.

\section{FACTORS DETERMINING BROMOCRIPTINE RESPONSE}

The degree of improvement due to bromocriptine was irrespective of the degree of patient disability and bromocriptine caused improvement in both slightly and severely disabled patients. In patients on levodopa or Sinemet, a slight reduction in the dosage of these treatments was made in four of seven patients during the year of bromocriptine treatment.

\section{LEVODOPA FAILURES}

Bromocriptine did not cause a useful degree of improvement in either of the two patients who had 


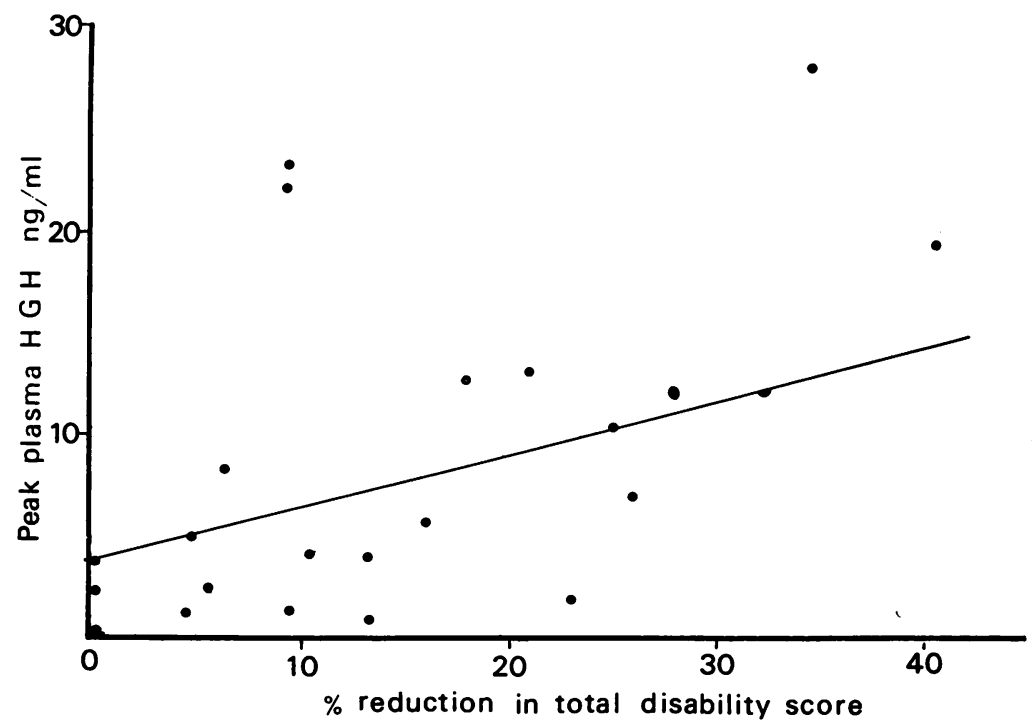

FIG. 2 Peak plasma growth hormone levels and percentage reduction in total disability score in seven patients with idiopathic Parkinson's disease, given separate dosages of bromocriptine, $12.5,25,50$, and $100 \mathrm{mg}(r=0.41, \mathrm{P}<0.05)$.

TABLE 2

MEAN DISABILITY SCORES ( \pm 1 SEM) IN 11 PATIENTS WITH IDIOPATHIC PARKINSON'S DISEASE BEFORE AND DURING ONE YEAR OF BROMOCRIPTINE TREATMENT

\begin{tabular}{|c|c|c|c|c|c|c|}
\hline & \multirow[b]{2}{*}{ Pre-bromocriptine } & \multicolumn{5}{|c|}{ Bromocriptine treatment (months) } \\
\hline & & 1 & 2 & 4 & 6 & 12 \\
\hline $\begin{array}{l}\text { Bromocriptine alone }(\mathrm{n}=4) \\
\text { Total disability score } \\
\text { Tremor } \\
\text { Akinesia } \\
\text { Rigidity } \\
\text { Posture } \\
\text { Bromocriptine dose }(\mathrm{mg})\end{array}$ & $\begin{array}{c}48 \pm 13 \\
2.8 \pm 1.6 \\
11.8 \pm 2.3 \\
6.6 \pm 2.4 \\
7.1 \pm 3.4 \\
-\end{array}$ & $\begin{aligned} 40 & \pm 13 \\
0.8 & \pm 0.4 \\
10.3 & \pm 2.2 \\
4.5 & \pm 2.0 \\
5.9 & \pm 3.4 \\
20 & \pm 8\end{aligned}$ & $\begin{array}{l}34 \pm 14 \\
1.3 \pm 0.6 \\
6.0 \pm 1.5 \\
4.8 \pm 2.4 \\
7.5 \pm 3.8 \\
19 \pm 5\end{array}$ & $\begin{array}{l}35 \pm 15 \\
1.3 \pm 0.5 \\
6.0 \pm 2.9 \\
4.8 \pm 2.3 \\
5.9 \pm 3.5 \\
21 \pm 3\end{array}$ & $\begin{array}{l}33 \pm 15 \\
1.4 \pm 0.6 \\
5.8 \pm 3.1 \\
4.1 \pm 1.8 \\
6.3 \pm 3.5 \\
18 \pm 1\end{array}$ & $\begin{array}{l}31 \pm 12 \\
0.6 \pm 0.6 \\
5.2 \pm 2.8 \\
3.4 \pm 1.1 \\
5.9 \pm 3.7 \\
39 \pm 17\end{array}$ \\
\hline $\begin{array}{l}\text { Bromocriptine plus levodop } \\
\text { Total disability score } \\
\text { Tremor } \\
\text { Akinesia } \\
\text { Rigidity } \\
\text { Posture } \\
\text { Bromocriptine dose (mg) }\end{array}$ & $\begin{aligned} 47 & \pm 4 \\
0.9 & \pm 0.7 \\
10.1 & \pm 0.7 \\
6.4 & \pm 0.6 \\
6.8 & \pm 1.5 \\
- & \end{aligned}$ & $\begin{array}{l}39 \pm 7 \\
0.1 \pm 0.1 \\
8.5 \pm 1.3 \\
5.0 \pm 1.1 \\
5.9 \pm 1.5 \\
28 \pm 4\end{array}$ & $\begin{array}{l}33 \pm 8 \\
0.4 \pm 0.4 \\
6.6 \pm 1.4 \\
3.4 \pm 1.1 \\
4.6 \pm 1.7 \\
29 \pm 5\end{array}$ & $\begin{array}{l}35 \pm 9 \\
0.3 \pm 0.3 \\
7.8 \pm 1.6 \\
4.4 \pm 0.8 \\
4.3 \pm 1.8 \\
30 \pm 5\end{array}$ & $\begin{array}{l}42 \pm 8 \\
0.9 \pm 0.8 \\
7.9 \pm 1.6 \\
4.4 \pm 0.8 \\
6.1 \pm 1.9 \\
28 \pm 8\end{array}$ & $\begin{aligned} 37 & \pm 7 \\
0.5 & \pm 0.4 \\
7.1 & \pm 1.5 \\
4.2 & \pm 0.7 \\
5.1 & \pm 1.9 \\
91 & \pm 4.6\end{aligned}$ \\
\hline
\end{tabular}

previously not responded to levodopa. In the four patients who had lost initial levodopa response, the addition of bromocriptine $40-90 \mathrm{mg}$ daily for periods of two to six months did not cause subjective improvement in any patient, although there was a $30 \%$ reduction in total disability score in a single patient. Bromocriptine $40-90 \mathrm{mg}$ daily did not cause nausea or neuropsychiatric complications in these patients. Levodopa dyskinesias increased in two patients after the addition of bromocriptine.

\section{LEVODOPA SWINGERS}

Diurnal response variations, related in time to levodopa treatment at intervals of four hours and to fluctuations in plasma dopa levels, occurred in five patients. The severity of this type of response swing was reduced in four of these five patients when bromocriptine 10-300 mg daily was added to treatment, and levodopa dosage reduced by one-third to a half. These four patients reported a subjective improvement in response swings, which occurred less frequently and 
were less severe while on bromocriptine, although, during periods of greatest response on combined treatment, the degree of improvement was no greater than when on levodopa alone, dyskinesias were unaltered or increased, and response swings due to dyskinesias and freezing episodes continued unchanged. One patient with response swings due to fluctuating plasma dopa levels did not improve when bromocriptine was added to levodopa.

It was not possible in any of these patients to replace totally levodopa with bromocriptine for prolonged periods as, despite high dosages of bromocriptine, the therapeutic response to this drug alone did not equal that previously caused by levodopa.

\section{BROMOCRIPTINE DYSKINESIAS}

In 24 subjects treated with bromocriptine for two to 12 months, dyskinesias occurred in four of eight patients given bromocriptine $20 \mathrm{mg}$ or higher dosages as a single treatment, but not in three subjects on lower dosages. Four patients improved on high dosages of bromocriptine (40-100 mg daily), but did not develop dyskinesias. Bromocriptine alone caused restlessness, orofacial dyskinesia, and chorea. In individual patients, the severity of dyskinesia increased with higher bromocriptine dosages. Dyskinesias occurred both in subjects who did, and others who did not, have an increase in plasma growth hormone concentration after bromocriptine.

In patients on levodopa, with levodopa-dyskinesias, in most cases the addition of bromocriptine without levodopa-dose reduction resulted in an increase in the severity of dyskinesia. Levodopainduced orofacial dyskinesia was made worse by the addition of bromocriptine, but akathisia was unaltered, and, in two patients, torticollis and rotatory trunk movements improved.

\section{SIDE-EFFECTS OF BROMOCRIPTINE}

In 37 patients treated with bromocriptine, side-effects prevented prolonged treatment in 13 subjects. Two subjects developed symptomatic postural hypotension after the initial bromocriptine dosage of $2.5 \mathrm{mg}$, hallucinations occurred in seven patients taking bromocriptine 5-25 mg daily (in one patient as a single treatment, and in six, combined with levodopa), and in four other patients, headache or increase in the severity of levodopa-dyskinesias prevented prolonged bromocriptine treatment. In these 13 patients, these symptoms could not be abolished totally by reduction in bromocriptine or levodopa dosage except at the expense of signs of increasing Parkinsonism. In an additional four subjects, there was no obvious clinical improvement on bromocriptine, and treatment was stopped.
In comparison with levodopa, emesis was not commonly caused by bromocriptine, occurring in only four patients. Nausea occurred 30-60 minutes after bromocriptine (5-20 mg) was given, and was of short duration, five to 15 minutes, unaccompanied by vomiting. Nasal stuffiness occurred in one patient, and sedation and lethargy in five, but these side-effects were not of sufficient severity to prohibit bromocriptine treatment.

In 11 patients treated for one year, and in others treated for shorter periods, there was no evidence of haematological or biochemical toxicity due to bromocriptine. Haemoglobin, WBC, ESR, Coombs test, blood urea, uric acid, electrolytes, glucose, bilirubin, aspartate aminotransferase, and plasma proteins were normal before and after treatment, although blood glucose was transiently raised in one patient, and blood urea in two. The ECG, chest radiograph, and urine analysis were not altered by bromocriptine treatment, although six patients had evidence of intermittent urinary infection.

Unlike Thorner (1975), we did not identify syndrome associated with bromocriptine overdosage, characterised by nausea and vomiting, severe hypotension, malaise, difficulty with cerebration, constipation, and involuntary repetitive yawning.

\section{DISCUSSION}

Bromocriptine $2.5-300 \mathrm{mg}$ daily is an effective antiParkinsonism drug that causes about a 20-30\% improvement in tremor, rigidity, akinesia, posturato deformity, and total functional disability scores. The? response to bromocriptine is rapid in onset, occurring within a few days of starting treatment, and tolerance to the anti-Parkinsonism action of bromocriptine does not develop during a year of treatment. The duration of action of a single oral dose of bromocriptine, six to eight hours, is longer than that of levodopa, two to four hours (Fuxe et al., 1974). In most patients bromocriptine in high dosages (100$300 \mathrm{mg}$ daily) is not quite so potent as average therapeutic doses of levodopa (1-3 g daily), although in some patients both drugs may be as active.

Most patients with Parkinson's disease respond to both bromocriptine and levodopa and in these subjects bromocriptine does not appear to have any practical advantage over levodopa. In patients who do not respond to levodopa, it is worth a trial of bromocriptine therapy, although in our experience these patients do not show a useful response to bromocriptine. The cause of levodopa failure in those patients we studied was not definitely established, although the correct diagnosis in two subjects may have been striatonigral degeneration, rather than Parkinson's disease. 
Bromocriptine is of definite value in the treatment of patients on levodopa who have response swings due to fluctuating dopa levels in the plasma and a much more stable response is achieved by combined bromocriptine-levodopa treatment. However, we were not able totally to replace levodopa by bromocriptine in these patients as the therapeutic effect of bromocriptine alone was less than that of levodopa. Bromocriptine probably does not alter other types of response swings due to freezing episodes or dyskinesias and, when the response to levodopa is limited by severe dyskinesias, bromocriptine treatment is not of value since it causes equally intense involuntary movements.

Bromocriptine mimics the action of levodopa and hence, by analogy, of dopamine, although bromocriptine is less potent than levodopa. The dopamine antagonist metoclopramide acts as a competitive antagonist to the anti-Parkinsonism and growth hormone effects of both levodopa and bromocriptine and we have also observed that metoclopramide pretreatment prevents hallucinations and nausea due to both drugs.

This evidence indicates that bromocriptine acts as a dopamine agonist within the central nervous system and there are several other indications that bromocriptine causes direct dopamine receptor stimulation in man. We have observed that bromocriptine is an effective anti-Parkinsonism drug in severely disabled patients, who are likely to have considerable dopaminergic neurone damage but intact dopamine receptors. Bromocriptine is a more effective anti-Parkinsonism drug than amphetamines or amantadine, both of which have presynaptic but not postsynaptic actions. Prolactin supression by levodopa may result from the action of dopamine on the pituitary cell (Takahara et al., 1974); like levodopa, bromocriptine lowers plasma prolactin levels. Further indirect evidence of dopamine receptor stimulation by bromocriptine is given by the finding that bromocriptine causes a reduction and not an increase in CSF homovanillic acid concentration. However, despite these different lines of evidence suggesting dopamine receptor stimulation, bromocriptine is likely to possess both pre- and post-synaptic actions at dopaminergic synapses in man.

Bromocriptine appears to be a less potent dopamine agonist than levodopa. However, the antiParkinsonism and growth hormone effects of levodopa may both be related to increases in noradrenaline as well as dopamine levels in the brain. Bromocriptine does not increase brain dopamine levels and is a noradrenergic antagonist (Corrodi et al., 1973).

Nigrostriatal and hypothalamic dopamine receptors are both intact in Parkinsonism and respond in a similar way to bromocriptine as shown by the finding that those subjects with Parkinsonism having a good clinical response to bromocriptine also achieve relatively high plasma levels of growth hormone and those with a poor response, low levels. This correlation of clinical response and plasma growth hormone levels was not, however, found in patients on levodopa.

Hypotension caused by dopamine is partly due to central effects and partly due to stimulation of peripheral vascular dopamine receptors with vasodilatation and a fall in peripheral resistance (McNay and Goldberg, 1966). In animals, hypotension due to dopamine is prevented by pretreatment with bulbocapnine but not pimozide; in contrast pimozide but not bulbocapnine abolishes the emetic response to dopamine (Settler et al., 1975). Since in man metoclopramide partially abolishes the central but not the hypotensive effects of levodopa and bromocriptine, central and peripheral dopamine receptors may be different in nature in both man and animals.

We gratefully acknowledge financial support and gift of bromocriptine from Sandoz, and the help of Dr G. Kennedy, Mrs P. Asselman, Mrs I. Jebson, and Mrs M. Spencer. A.G.D. was supported by a grant from King's College Hospital and The Institute of Psychiatry Research Committees.

REFERENCES

Calne, D. B., Teychenne, P. F., Claveria, L. E., Eastman, R., Greenacre, J. D., and Petrie, A. (1974). Bromocriptine in parkinsonism. British Medical Journal, 4, $442-445$.

Cammani, F., Massara, F., Belforte, L., and Molinatti, G. M. (1975). Changes in plasma growth hormone levels in normal and acromegalic subjects following administration of 2-bromo-alpha-ergocryptine. Journal of Clinical Endocrinology, 40, 363-366.

Corrodi, H., Farnebo, L-O., Fuxe, K., and Hamberger, B. (1975). Effect of ergot drugs on central 5-hydroxytryptamine neurones. European Journal of Pharmacology, 30, 172-181.

Corrodi, H., Fuxe, K., Hökfelt, T., Lidbrink, P., and Ungerstedt, U. (1973). Effect of ergot drugs on central catecholamine neurones. Journal of Pharmacy and Pharmacology, 25, 409-412.

Debono, A. G., Marsden, C. D., Asselman, P., and Parkes. J. D. (1976). Bromocriptine and dopamine-receptor stimulation. British Journal of Clinical Pharmacology. (In press.)

Fuxe, K., Corrodi, H., Hökfelt, T., Lidbrink, P., and Ungerstedt, U. (1974). Ergocornine and 2 Brergocryptine: evidence for prolonged dopamine receptor stimulation. Medical Biology, 52, 121-132. 
Johnson, A. M., Loew, D. M., and Vigouret, J. M. (1976). Stimulant properties of bromocryptine on central dopamine receptors in comparison to apomorphine (+)-amphetamine and 1-dopa. British Journal of Pharmacology, (1966). 56, 59-68.

McNay, J. L., and Goldberg, L. I. (1966). Comparison of the effects of dopamine, isoproterenol, norepinephrine and bradykinin on canine renal and femoral blood flow. Journal of Pharmacology and Experimental Therapeutics, 151, 23-31.

Marsden, C. D., Barry, P. E., Parkes, J. D., and Zilkha, K. J. (1973). Treatment of Parkinson's disease with methyldopa combined with 1-alphamethyldopahydrazine, an extracerebral inhibitor of dopa decarboxylase. Journal of Neurology, Neurosurgery, and Psychiatry, 36, 10-14.

Marsden, C. D., and Parkes, J. D. (1976). On-off effects in patients with Parkinson's disease on chronic levodopa therapy. Lancet, 1, 292-296.

Peringer, E., Jenner, P., Donaldson, I., Marsden, C. D., and Miller, E. (1976). Metoclopramide and dopamine receptor blockade. Neuropharmacology, 15, 463-466.

Pozo, E., Brun del Re, R., Varga, L., and Friesen, H. (1972). The inhibition of prolactin secretion in man by CB154 (2 Br-alpha-ergocryptine). Journal of Clinical Endocrinology, 35, 768-771.

Schalch, D. S., and Parker, M. L. (1964). A sensitive double antibody immunoassay for human growth hormone in plasma. Nature (Lond), 203, 1141-1142.

Settler, P. E., Pendleton, R. G., and Finlay, E. (1975). The cardiovascular actions of dopamine and the effects of central and peripheral catecholaminergic receptor blocking drugs. Journal of Pharmacology and Experimental Therapeutics, 192, 702-712.

Takahara, J., Arimura, A., and Schally, A. V. (1974). Suppression of prolactin release by a purified porcine PIF preparation and catecholamines infused into a hypophyseal portal vessel. Endocrinology, 95, 462-465.

Thorner, M. O. (1975). Dopamine is an important neurotransmitter in the human nervous system. Lancet, 1 , 662-665. 